\title{
SSinteza
}

Impact of Internet on Business Activities in Serbia and Worldwide

Uticaj Interneta na poslovanje u Srbiji i svetu

DOI: 10.15308/SINTEZA-2014-402-406

\section{KREIRANJE PITANJA I PROVERA ZNANJA ELEKTRONSKIM TESTIRANJEM NA PLATFORMI ZA E-UČENJE}

\author{
Ivan Z. Tomić ${ }^{1}$, Katarina N. Tomić ${ }^{1}$, Aleksandar N. Petrović ${ }^{2}$ \\ ${ }^{1}$ Visoka škola strukovnih studija za vaspitače Kruševac, Srbija \\ ${ }^{2}$ Vojna akademija Beograd
}

\begin{abstract}
:
Ocenjivanje znanja jedan je od najvažnijih elemenata procesa učenja, zato što obezbeđuje informacije o tome u kojoj meri su postignuti unapred postavljeni edukativni standardi. Procenjivanje znanja i veština studenata odvija se na različite načine, korišćenjem raznovrsnih tehnika. Izbor tehnike testiranja, kao i pristup procesu evaluacije znanja od strane nastavnika značajno utiču kako na konkretno postignuće, tako i na opšti odnos studenata prema učenju i napredovanju. Da bi se kontrolisalo angažovanje materijalnih i kadrovskih resursa u procesu testiranja, neophodno je primenjivati efikasnije i ekonomičnije načine pripreme i zadavanja testova, u čemu značajnu ulogu imaju savremene informacione tehnologije i tehnike elektronskog testiranja i ocenjivanja. Osim pomenutih prednosti, elektronsko testiranje obezbeđuje i mogućnost češćeg ponavljanja gradiva i samoocenjivanja rešavanjem probnih testova, putem odgovaranja na postavljena pitanja uz trenutni feedback za tačne, ali i pogrešne odgovore.

U radu će biti prikazan jedan od modela kreiranja različitih tipova pitanja u tekst procesoru, kreiranje xml fajla i uvoz pitanja u platformu za e-učenje MOODLE. Kreiranje testova i ocenjivanje studenata potrebno je vršiti u kontrolisanim uslovima.
\end{abstract}

\section{Key words: \\ elektronsko učenje, elektronsko testiranje, Moodle, Word dodatak.}

\section{UVOD}

Neizostavan deo nastavnog procesa u visokom obrazovanju predstavlja testiranje i ocenjivanje postignuća studenata, korišćenjem različitih postupaka merenja i kategorizacije. Ocenjivanje znanja podrazumeva donošenje suda o nivou i kvalitetu usvojenih znanja, ali u skladu s načelima postmoderne didaktike i eklektičkog pristupa nastavnom procesu, koji se oslanja na individualizaciju u ocenjivanju i emancipaciju položaja učenika/studenta u interakciji s ocenjivačem, ono mora biti zasnovano na „eksplicitnom definisanju kriterijuma ocenjivanja, koje mora, osim objektivnog pokazatelja usvojenih znanja, veština i navika da obuhvati i postupke, načine i metode kako se do njih došlo" [1]. U skladu s tim i s obzirom na ubrzano prodiranje savremenih informacionih tehnologija i računarskih sistema u obrazovni proces, očekivano je da kreiranje i masovno korišćenje platformi za elektronsko učenje postane sastavni deo visokoškolskog obrazovanja, ne samo u didaktičkom smislu, kao sredstvo prezentacije i način usvajanja novih znanja, već i kroz metode i postup-
U najopštijem određenju, samo elektronsko učenje obuhvata složene tehnologije i akademske servise namenjene procesima učenja i podučavanja [2]. Savremeni pristupi u elektronskom učenju obezbeđuju veću dinamiku nastavnog procesa i sofisticirano prilagođavanje obuke potrebama i predznanju studenata, jer angažuju mnoge inovativne načine obrađivanja gradiva, koji su bili nedostupni tradicionalnim nastavnim konceptima - virtuelna učionica i konferencija, on-line obuka i učenje na daljinu, raznovrsni audio i video materijali, kompjuterski programi i sl. Sve te prednosti omogućavaju ovom otvorenom, ali koherentnom sistemu da proširi granice podučavanja i prostorno i vremenski, omogućavajući studentima da u eri prave eksplozije informacija vrše smislenu organizaciju dostupnog materijala i ovladavaju ekonomičnim strategijama učenja i tehnikama samousmeravanja u učenju, prilagođavajući sam proces svojim potrebama i interesovanjima. Pored prezentacije novih znanja, platforme za elektronsko učenje, kao što je već rečeno, omogućavaju i kreiranje modela za testiranje i proveru znanja, usaglašavajući ciljeve ocenjivanja sa novom paradigmom multimedijalnog pristupa obučavanju, kao i sa narastajućim zahtevima savremenog informatičkog društva. 


\section{TESTIRANJE I OCENJIVANJE}

Savremeni modeli univerzitetskog obrazovanja, kao što je kod nas implementiran Bolonjski sistem, podrazumevaju promenu uobičajene ex catedra paradigme jednostranog prenošenja znanja predavača pasivnim konzumentima, ka sve većoj aktivnoj uključenosti studenata kroz interaktivnu nastavu, samostalne studentske radove - prezentacije i kontinuirano praćenje postignuća tokom čitave nastavne godine/semestra [3]. Konstantna evaluacija stečenih veština i znanja je nešto što i sami studenti ističu kao posebnu prednost Bolonjskog sistema i nešto što značajno olakšava usvajanje obimnih nastavnih sadržaja [4].

Hant i sar. navode da je procenjivanje znanja jedan od krucijalnih elemenata procesa učenja, koji obezbeđuje veoma korisne informacije o tome u kojoj meri su postignuti unapred postavljeni edukativni standardi. Ocena studentu pruža uvid u kvalitet sopstvenog napredovanja, ali može biti i značajno motivaciono sredstvo, koje će naterati studenta da uloži dodatne napore i ispravi detektovane greške u učenju. S druge strane, autorka naglašava da ocene postignuća daju uvid i u kvalitet zahteva konkretnog studijskog programa i njihovu usklađenost sa potrebama i mogućnostima ciljne grupe studenata [5].

Procenjivanje znanja i veština studenata odvija se na različite načine, korišćenjem raznovrsnih metoda i tehnika. Izbor tehnike testiranja, kao i pristup procesu evaluacije znanja od strane pojedinih nastavnika značajno utiču kako na konkretno postignuće na testovima i ispitima, tako i na opšti pristup studenata učenju i napredovanju. Ovaj specifičan interaktivni odnos studenta i porcenjivača upućuje na potrebu pažljivog odabira tehnike i pristupa u ocenjivanju, s obzirom na to da ocenjivanje značajno utiče na dalje postignuće. Istraživanja pokazuju da među studentima postoje preferencije kada su u pitanju tehnike procenjivanja znanja, pa tako studenti koji imaju nizak prag anksioznosti i koji su skloniji aktivnoj konceptualnoj analizi i dubokom razumevanju onog što se uči, imaju više samopouzdanja i preferiraju zatvorene tehnike testiranja, dok su esejska pitanja i otvorene test-forme pogodnije za ansioznije studente, koji su skloni površnom i rutinskom memorisanju edukativnih sadržaja, koje doživljavaju kao napor nametnut spolja (ekstrinzički motivisani) [6] .

Poseban problem u procesu evaluacije znanja studenata, kako navode Radenković i Lazarević jeste ubrzan porast obima znanja, a samim tim i produžavanje vremena testiranja, koje postepeno iziskuje sve veće angažovanje materijalnih i kadrovskih resursa, tako da je, po autorima, neophodno pronaći efikasnije i ekonomičnije načine ocenjivanja, kojima bi se smanjio pritisak i izvršila „ušteda ljudskih resursa". Rešenje pomenutih problema autori prepoznaju u korišćenju informacionih tehnologija i tehnika elektronskog testiranja i ocenjivanja [7]

\section{ELEKTRONSKO TESTIRANJE}

Za najbolje rezultate $\mathrm{u}$ nastavi danas je neophodno koristiti sva dostupna dostignuća savremenih informaci- onih tehnologija. Elektronsko testiranje u visokoškolskim ustanovama najčešće se praktikuje kao neizostavan deo platformi za elektronsko učenje, čija je upotreba danas uobičajena [8]. Tehnike elektronskog testiranja i ocenjivanja studenata imaju brojne prednosti. Osim što obezbeđuju značajne uštede vremena i resursa, omogućavanjem jeftinih i češćih ispitivanja velikog broja studenata, one podrazumevaju i veću subjektivnost i tačnost u ocenjivanju, jer uklanjaju potencijalne greške ljudskog faktora. Od nedostataka vredi napomenuti da se ovakav vid provere znanja može percpirati kao dehumanizujući, zato što ne zahteva nužno prisustvo nastavnika i minimalizuje neposredne kontakte sa ispitivačem. Tradicionalno usmeno testiranje u tom smislu nudi veće mogućnosti, zato što obezebeđuje neposredan kontakt sa ispitanikom i pruža informacije o intelektualnim sposobnostima i karakteristikama ličnosti ispitanika, što se ne može ostvariti tehnikama elektronskog testiranja [9]. Isto tako, s obzirom na to da se najčešće primenjuju test pitanja sa višestrukim izborom, postoji mogućnost oslanjanja na pogađanje tačnih odgovora, koje ne mora da da validne rezultate, koji odgovoaraju stvarnom znanju. Takođe, elektronsko testiranje zahteva savremenu računarsku opremu, kreiranje i održavanje baza podataka, kao i rešavanje pitanja sigurnosti pristupa i sprečavanje angažovanja studenata u nedozvoljenim radnjama prilikom verifikacije njihovog identiteta i samog rešavanja test pitanja.

\section{PLATFORMA MOODLE}

U visokoškolskim ustanovama u Srbiji, već nekovreme u upotrebi je platforma za elektronsko učenje- MOODLE, koja se koristi više kao alat za distribuciju elektronskih sadržaja studentima, nego kao moćan alat za e-učenje. Vrlo mali broj programa je akreditovan za e-učenje, što pokazuje relativnu nezainteresovanost za ovu oblast u našoj sredini, kako samih institucija, tako i države i ministarstva. Inače, MOODLE platforma je besplatan (open source) i veoma atraktivan softver namenjen elektronskom upravljanju kursevima, koji nudi širok spektar modula (aktivnosti) namenjenih on-line učenju i podučavanju.

\section{Testovi}

Testovi su samo jedan modul (funkcionalnost) u okviru platforme za e-učenje, kojim se može izmeriti napredak studenata. Kreiranju testova za elektronsku proveru znanja prethodi veoma naporan posao osmišljavanja i kreiranja samih pitanja, da bi se formirala kvalitetna baza različitih tipova pitanja, nakon čega se sam test vrlo lako i brzo pravi.

\section{Pitanja}

MOODLE omogućava da se pitanja uvezu iz različitih formata i platformi za e-učenje. Takođe, moguće je pravljenje novih pitanja i na samoj platformi za e-učenje, s tim da je proces vrlo spor i zamoran. 
Od tipova pitanja, u upotrebi su pitanja otvorenog tipa (esejski zadaci) i pitanja zatvorenog tipa (pitanja alternativnog izbora, pitanja višestrukog izbora, pitanja povezivanja, pitanja dopunjavanja, pitanja sa proračunavanjem, pitanja sa brojem kao odgovorom i sl.), čije korišćenje u svakom konkretnom slučaju određuje sam ispitivač, u skladu sa ciljem i potrebama ispitne situacije (pre-test, test, kolokvijum, ispit i sl.).

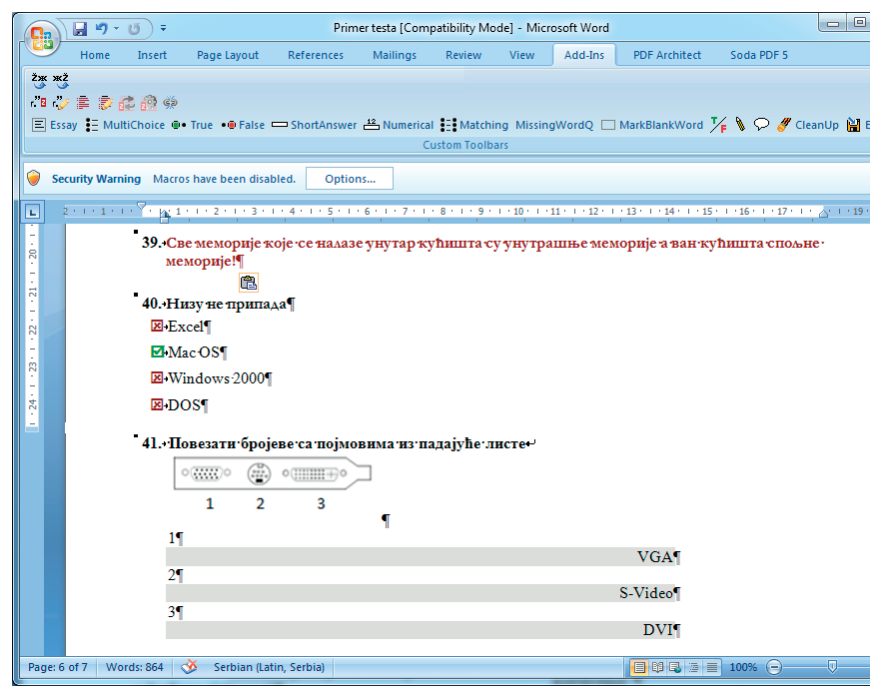

Fig. 1. Izgled taba Add-Ins

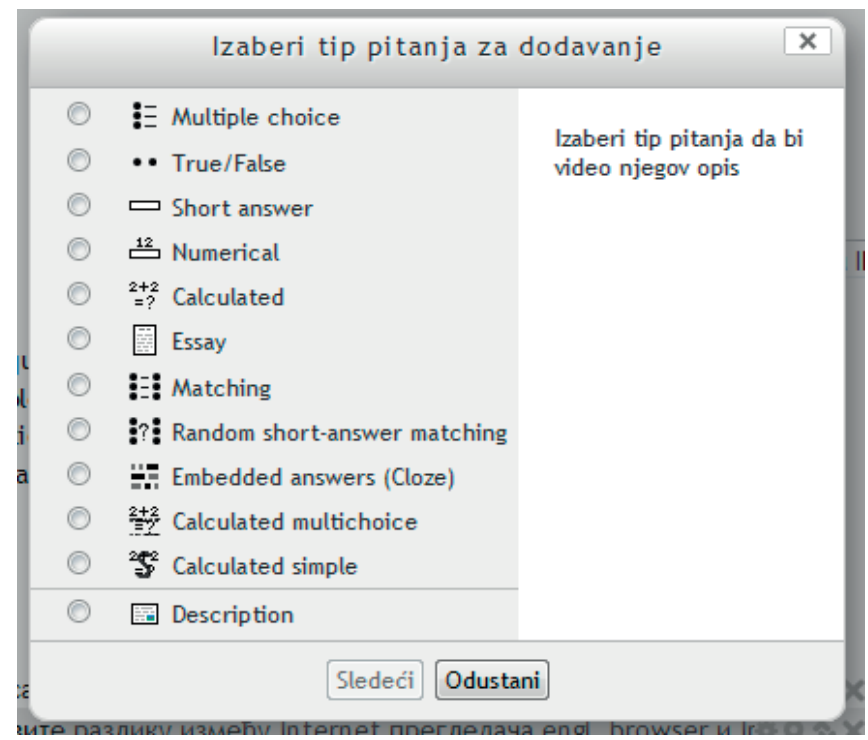

Fig. 2. Vrste pitanja u MOODLE-u

Umesto da sva budu na jednom velikom spisku, pitanja mogu biti organizovana u kategorije i potkategorije. Svaka kategorija ima kontekst koji određuje gde pitanja iz nje mogu da se koriste:

- Kontekst aktivnosti - pitanja su dostupna samo unutar određene aktivnosti

- Kontekst kursa - pitanja su dostupna u svim aktivnostima određenog kursa

- Kontekst kategorije kursa - pitanja su dostupna u svim aktivnostima i kursevima određene kategorije kurseva

- Kontekst sistema - pitanja su dostupna u svim kursevima i aktivnostima na sajtu

Kategorije se koriste i za nasumično izabrana pitanja, budući da se ona biraju iz određenih kategorija[10].
MOODLE podržava i izvoz pitanja koja su na platformi u tri formata:

- GIFT format

- Moodle XML format

- XHTML format

Nove, dograđene verzije MOODLE platforme obezbeđuju studentima širok spektar pogodnosti prilikom testiranja, omogućavajući npr. da se istom pitanju pristupi više puta, zatim davanjem trenutnog fidbeka za svako pitanje, kao i pružanjem mogućnosti da za svako pitanje naznače u kojoj meri su sigurni u svoj odgovor. Na kraju samog testa, neposredno pre podnošenja, moguće je postaviti pregled čitavog testa, gde su naznačena pitanja koja su eventualno preskočena.

\section{Pravljenje pitanja u off line režimu}

U najvećem broju slučajeva prilikom pravljenja baze pitanja već postoji neki tekst iz koga se ona izvlače, a to su vrlo često i pitanja koja su nastavnici koristili na testovima u klasičnoj nastavi, pa je zgodno da se ona prave u tekst procesoru, jer su to i alati koji su svima su dobro poznati.

Sintaksa za pisanje pitanja u nekom od standardnih tekstualnih formata sa kojima radi MOODLE, nije tako komplikovana, pa je pitanja moguće napisati u bilo kom tekst procesoru (npr. Notepad-u), ali je daleko jednostavnije korišćenjem šablona sa makrom. Na internetu je moguće pronaći šablone za dva najpopularnija tekst procesora: Microsoft Office Word [11] i Open/Libre Office Writer [12]. Po preuzimanju arhive, potrebno ju je otpakovati na neku spoljnu memoriju, pri čemu se pojavljuje više fajlova, među kojima se nalaze: uputstvo, primer, šablon za Word. Startovanjem šablona potrebno je omogućiti korišćenje ugrađenog makroa. U okviru taba Add-Ins, postoje alati za stilizovanje različitih tipova pitanja. Izborom alata kreiramo pitanje i ponuđene odgovore.

Na slici 2. prikazana su tri primera pitanja: ponuđen odgovor, koji je netačan, pitanje sa višestrukim izborom i povezivanje elemenata, gde je dodata i slika. Pre pravljenja xml fajla, potrebno je očistiti dokument od suvišnih formatiranja izborom opcije "Clean Up“ i nakon toga, ukoliko je sve u redu, fajl se snima u istom folderu gde se nalazi i šablon, posle čega možemo napraviti xml fajl izborom opcije „Export“. Takođe, i xml fajl će biti smešten u folder gde se nalazi šablon.

\section{PRIMER KORIŠĆENJA}

U Visokoj školi strukovnih studija za vaspitače u Kruševcu već nekoliko godina koristi se platforma za e-učenje MOODLE, prvenstveno za informisanje studenata, vezano za kurseve koji se realizuju na tradicionalni način. $\mathrm{Na}$ taj način, tehnologija za e-učenje postaje dostupna zainteresovanim nastavnicima i stvaraju se uslovi za obuku većeg broja nastavnika za njeno korišćenje.

Uvoz pitanja u MOODLE iz xml fajla vrši se u predhodno kreiranu kategoriju, jednostavnim izborom željenog fajla. Na taj način, stvaraju se uslovi da se za budući test pitanja biraju nasumično, i za svakog studenta kreiraju njihove specifične kombinacije. 

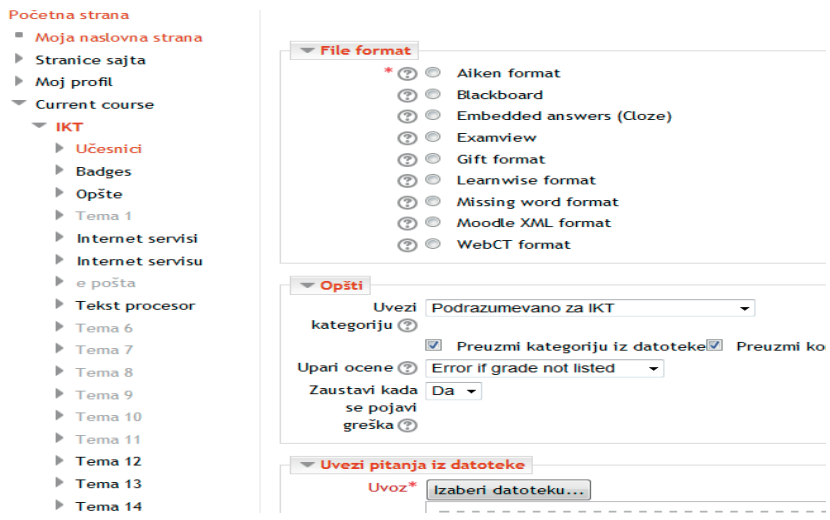

Fig. 3. Izgled aplikacije za uvoz pitanja u MOODLE

Pri kreiranju testa, nastavnik može izvršiti takva podešavanja da se testiranje vrši u kontrolisanim uslovima tj. u definisano vreme, sa ograničenim trajanjem izrade testa, pristupom preko određene IP adrese ili opsega, određenim brojem omogućenih pokušaja rešavanja testa, pristupe testu uz zahtevani unos lozinke i slično.

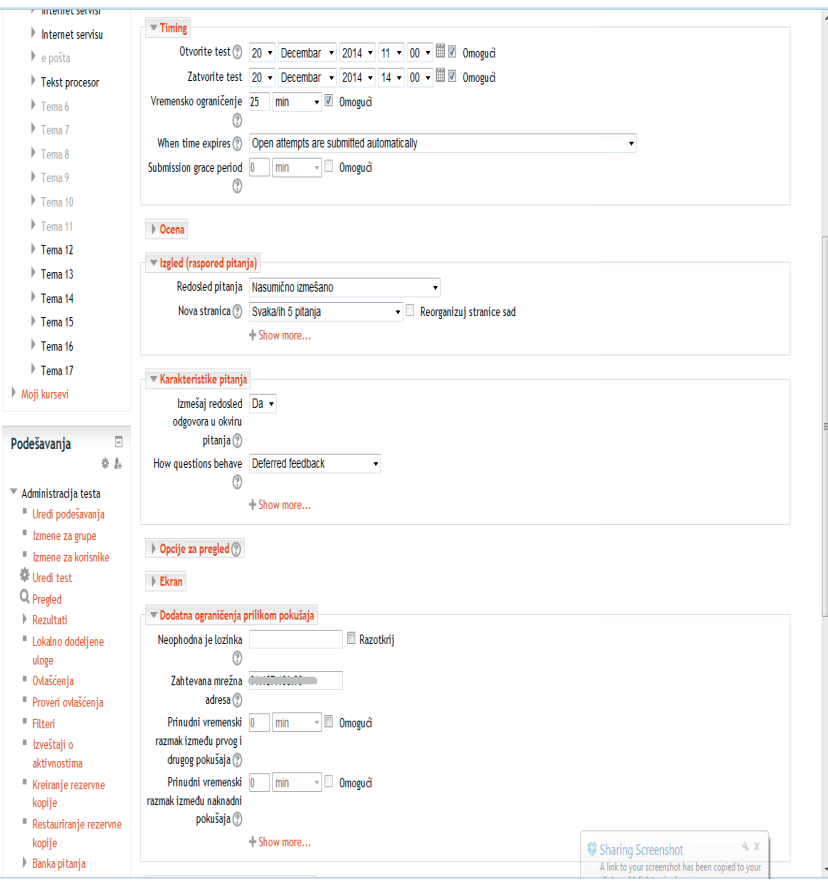

Fig. 4. Izgled aplikacije za podešavanje testa

\section{Scenario bezbednog testiranja}

Da bi se rešila bezbednosna pitanja i omogućilo nesmetano izvođenje testiranja, omogućena su podešavanja da student može samo jednom da pristupi testu, sa zadate IP adrese u određenom vremenskom intervalu. Zavisno od broja pitanja, zadaje se i koliko vremena student ima na raspolagaju za rešavanje test pitanja. Broj pitanja po jednoj strani se može podesiti, kao i to da li se omogućava vraćanje na prethodnu stranicu sa pitanjima ili ne. U našem slučaju, broj pitanja na jednoj stranici je podešen na 5 i student ne može da se vrati na prethodnu stranicu, čime se sprečava dogovaranje studenata, kada su na kraju testa i prepravka datih odgovora.

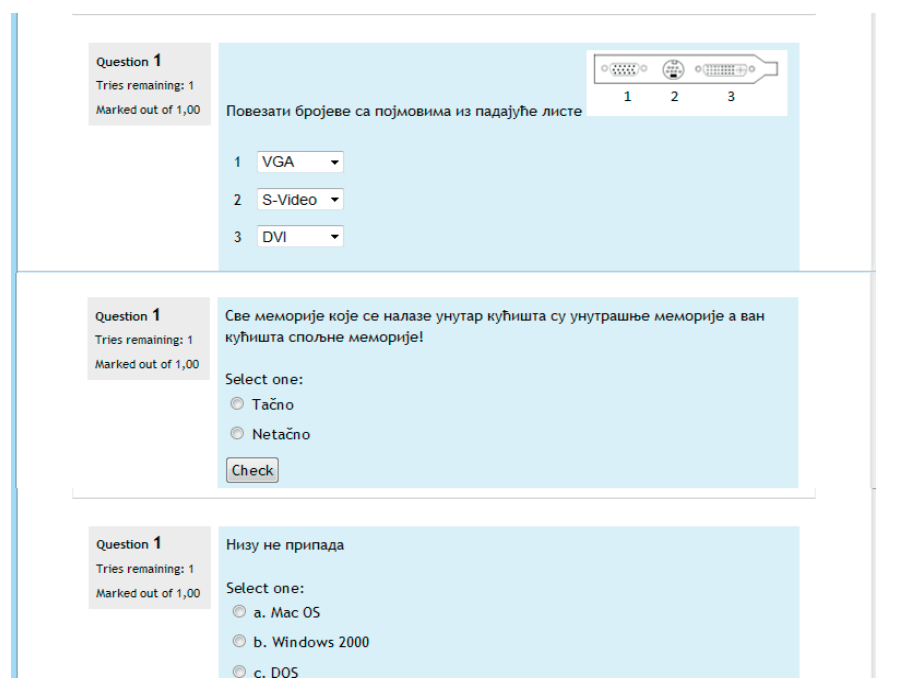

Fig. 5. Izgled stranice sa pitanjima iz ugla studenta

Studenti ulaze u računarsku učionicu i prijavljuju se na platformu MOODLE sa svojim korisničkim imenom i lozinkom i započinju test, nakon čega ih je neophodno identifikovati, da se ne bi desilo da jedan student radi test u tuđe ime (sa tuđim korisničkim imenom i lozinkom). Po završetku izrade svih pitanja, student predaje test i istovremeno dobija rezultate testa, kao i povratnu informaciju gde je pogrešio i šta je tačan odgovor.

\section{ZAKLJUČAK}

Primenom elektronskog testiranja možemo ostvariti značajnu uštedu vremena potrebnog za testiranje i ocenu postignuća na testu, što za posledicu ima mogućnost povećavanja broja (frekvencije) provera - testiranja, a samim tim i poboljšanje kvaliteta nastavnog procesa obezbeđivanjem kontinuirane evaluacije usvojenih znanja. Elektronsko testiranje se može koristiti kao priprema studenata (samoevaluacija) za tradicionalna testiranja. Umesto klasične podele testovnih kombinacija na grupe, npr. 2-4 različite kombinacije ispinih pitanja, elektronski test omogućava individualnu kombinaciju pitanja za svakog studenta randomiziranim generisanjem (slučajnim izborom) ispitnih kombinacija iz postojeće baze pitanja, čime se skoro potpuno sprečava prepisivanje odgovora od drugih i obesmišljava nedozvoljena komunikacija među studentima na ispitu. Rezultati pojedinačnih testova izračunavaju se veoma brzo i lako analizom i automatskim generisanjem tačnih odgovora, pri čemu se obezbeđuje momenalna povratna informacija, koja daje korisne podatke o trenutnom nivou na kom se nalazi svaki pojedini student i omogućava različita međusobna poređenja, kako unutar same studentske grupe, tako i šire, sa sličnim studijskim grupama na drugim visokoškolskim ustanovama.

\section{LITERATURA}

[1] R. Damjanović, "Teze za novu dokimološku paradigmu," Metod. Ogl., vol. 11, no. 2, pp. 111-116, Jan. 2005.

[2] N. Doukas and A. Andreatos, "Advancing Electronic Assessment.," Int. J. Comput. Commun. Control, vol. 2, no. 1, 2007. 
[3] N. Predrag, "Studentske prezentacije kao oblik nastave engleskog jezika,” Pedagoš. Stvarn., vol. 54, no. 9-10, pp. 981-989.

[4] R. Branka, M. Slobodanka, and G. Olivera, "Analiza mišljenja studenata Prirodno-matematičkog fakulteta o pozitivnim i negativnim stranama koncepta Bolonjskog sistema," Zb. Rad. Učit. Fak. Užice, no. 14, pp. 85-98.

[5] N. Hunt, J. Hughes, and G. Rowe, "Formative automated computer testing (FACT)," Br. J. Educ. Technol., vol. 33, no. 5, pp. 525-535, 2002.

[6] K. Struyven, F. Dochy, and S. Janssens, "Students' perceptions about evaluation and assessment in higher education: A review 1," Assess. Eval. High. Educ., vol. 30, no. 4, pp. 325-341, 2005.

[7] S. Radenković and S. Lazarević, "Sistem za evaluaciju znanja studenata kao podrška fleksibilnoj obuci," Info M, vol. 5, no. 17 , pp. $17-21$.
[8] W. Bieniecki, J. Stańdo, and S. Stoliński, "Information technologies in a process of examination in Poland," Inf. Syst. Manag. VII, p. 29.

[9] E. Ventouras, D. Triantis, P. Tsiakas, and C. Stergiopoulos, "Comparison of oral examination and electronic examination using paired multiple-choice questions," Comput. Educ., vol. 56, no. 3, pp. 616-624, 2011.

[10] "Question categories." [Online]. Available: http://docs. moodle.org/25/en/question/category. [Accessed: 09-Mar2014].

[11] "Moodle.org: Old modules and plugins." [Online]. Available: https://moodle.org/mod/data/view.php?rid=578. [Accessed: 10-Mar-2014].

[12] “GIFT format - MoodleDocs.” [Online]. Available: http:// docs.moodle.org/24/en/GIFT_format. [Accessed: 10-Mar2014].

\section{CREATING QUESTIONS AND EXAMINATION ON THE PLATFORM FOR E-LEARNING}

\begin{abstract}
:
Learning assessment is one of the most important elements of the learning process, because it provides information about the extent to which it has achieved preset educational standards. Assessment of knowledge and skills of students is conducted in various ways, using different techniques. The choice of testing techniques, and access to the evaluation of knowledge by teachers significantly affect both the concrete achievements, as well as the general attitude of students towards learning and improvement. In order to control the engagement of the material and human resources in the testing process, it is necessary to apply efficient and cost-effective ways of preparing and setting tests, in which modern information technologies and techniques of electronic testing and evaluation play an important role. In addition to the aforementioned benefits, electronic testing provides the possibilities for more frequent repetition of materials and self-assessment by using pilot tests and answering questions with immediate feedback for correct as well as incorrect answers.

This paper presents a model to create different types of questions in a word processor, create an XML file and import questions into a platform for e - learning MOODLE. Creating tests and evaluation of students should be done in a controlled environment.
\end{abstract}

\section{Key words:}

e-learning,

electronic examination, Moodle, Word Add-ins. 